\title{
DEGRADABILIDADE IN SITU DAS FRAÇÕES FIBROSAS DA SILAGEM DE SORGO
}

\author{
DANIEL ANANIAS DE ASSIS PIRES ${ }^{1}$, LÚCIO CARLOS GONÇALVES ${ }^{2}$, JOSÉ AVELINO \\ SANTOS RODRIGUES ${ }^{3}$, DIOGO GONZAGA JAYME ${ }^{4}$, ROBERTO GUIMARÃES \\ JÚNIOR ${ }^{5}$, NORBERTO MARIO RODRIGUEZ ${ }^{2}$, IRAN BORGES ${ }^{2}$, ANA LUÍZA COSTA \\ CRUZ BORGES ${ }^{2}$, CRISTIANO GONZAGA JAYME ${ }^{6}$, POLIANA ROCHA FRAGA \\ BOTELHO $^{7}$ e LUCIANA OLIVA BARBOSA LIMA ${ }^{8}$
}

${ }^{1}$ Professor do Departamento de Ciências Agrárias do curso de Zootecnia - Unimontes. Rua Cirilo Barbosa, $n^{\circ}$ 220A, Centro. Janaúba/MG - CEP: 39440-000. Tel: (38)3821-2756,piresdaa@gmail.com ${ }^{2}$ Professor do Departamento de Zootecnia da Escola de Veterinária da UFMG. AV. Antônio Carlos 6627, Pampulha. Belo Horizonte/MG - CEP: 30123-970.

${ }^{3}$ Pesquisador da Embrapa Milho e Sorgo, MG 424 Km 45, C.P. 151, Cep. 35701-970. Sete Lagoas/MG. ${ }^{4}$ Professor CEFET - Uberaba - MG

${ }^{5}$ Pesquisador da Embrapa Cerrados - Br 020, Km 18 - Cx. P. 08223 Cep. 73310-970 - Planaltina, DF. ${ }^{6}$ Doutor em Zootecnia pelo Depto. de Zootecnia da Escola de Veterinária da UFMG. Av. Presidente Antônio Carlos 6627, CP 567, CEP 30161-970.

${ }^{7}$ Mestranda em Zootecnia na área de Nutrição e Produção de Ruminantes - Unimontes - MG.

${ }^{8}$ Graduanda em Zootecnia, no Campus de Janaúba - Unimontes - MG

Revista Brasileira de Milho e Sorgo, v.8, n.2, p.175-185, 2009

RESUMO - O objetivo deste experimento foi estudar a degradabilidade in situ e a cinética de degradação da fibra em detergente neutro (FDN) e fibra em detergente ácido (FDA) das silagens de quatro genótipos de sorgo, com presença e ausência de tanino nos grãos. Foi utilizado um delineamento experimental de blocos ao acaso, em esquema de parcelas subdivididas, sendo os animais os blocos, as silagens as parcelas e os tempos de incubação as subparcelas. As médias foram comparadas pelo teste SNK, a 5\% de probabilidade. Após 96 horas de incubação, as degradabilidades da FDN e FDA variaram de 32,22 a $56,07 \%$ e de 26,40 a 54,40\%, para as silagens do BR700 e CMSXS165, respectivamente. A presença de tanino nos grãos comprometeu a degradabilidade ruminal da FDN e FDA das silagens de sorgo.

Palavras-chave: degradabilidade, ruminantes, silagem, sorgo, valor nutricional.

\section{IN SITU DEGRADABILITY OF THE FIBROUS FRACTIONS OF SORGHUM SILAGE}


ABSTRACT - The objective of this experiment was to study in situ degradability and fermentation kinetics parameters of the neutral detergent fiber (NDF) and acid detergent fiber (ADF) of the silages of four sorghum genotypes, with and without tannin in the grain. A randomized block in split plot design was applied, using animals as blocks, silages as splits and time as sub-splits. Means were compared by SNK test $(\mathrm{p}<0.05)$. After 96 hours incubation, NDF and NDA effective degradability ranged from 32.22 to $56.07 \%$ and from 26.40 to $54.40 \%$, for silages BR700 and CMSXS165, respectively. The results showed the negative effect of tannin on the ruminal degradability of NDF and ADF of sorghum silages.

Key words: degradability, nutritional value, ruminant, silage, sorghum

A utilização de forragens pelos ruminantes apresenta interações complexas entre os diversos componentes da planta e os microrganismos do retículo-rúmen. Nesse aspecto, a qualidade da forragem pode ser expressa em termos de três características próprias: a extensão da digestão potencial, a taxa de fermentação e a taxa de redução do tamanho de partícula. Essas três características estão envolvidas no controle do consumo voluntário e pelo menos as duas primeiras podem ser estimadas usando-se a técnica in situ do saco de náilon.

A determinação de parâmetros cinéticos, relacionados com a degradabilidade ruminal dos nutrientes, é difícil de ser feita in vivo e é de fundamental importância na avaliação nutricional de alimentos para ruminantes (Nocek (1988).

A técnica in situ consiste em colocar amostras de alimento em uma série de sacos de náilon e incubá-los no rúmen de animais fistulados. Em tempos apropriados, os sacos são retirados e lavados (Barbosa, 1996). Dessa forma, pode-se avaliar a qualidade dos alimentos pela determinação da quantidade de amostra que é degradada e a taxa em que essa degradação ocorre (Thiago, 1994).

Essa técnica tem sido preferida com relação à metodologia in vivo por ser menos trabalhosa, com menor demanda de recursos financeiros e menor quantidade de alimento e, principalmente, por descrever a participação da degradação ruminal na digestibilidade total dos alimentos (Huntington e Givens, 1995).

Nos estudos de digestibilidade, os resultados obtidos in vivo são mais realísticos que os métodos disponíveis em laboratório, onde se tenta reproduzir os processos naturais do rúmen, mas dependem de técnicas sofisticadas, como o uso de marcadores, instalações adequadas e tempo. O advento da técnica in situ utilizandose sacos de náilon em animais fistulados no rúmen permitiu a avaliação rápida e simples da degradação do material em função do tempo de incubação ruminal, apresentando alta correlação com resultados obtidos em experimentos in vivo. 
Dessa forma, o conhecimento da degradabilidade in situ dos componentes nutricionais de cultivares de sorgo com e sem tanino nos grãos é fundamental na avaliação dessa forrageira para produção de silagem( Van Soest et al.,1994).

O objetivo deste experimento foi estudar a degradabilidade in situ e a cinética de degradação da fibra em detergente neutro (FDN) e fibra em detergente ácido (FDA) das silagens de quatro genótipos de sorgo, com presença e ausência de tanino nos grãos.

\section{Material e Métodos}

Quatro tipos de sorgo foram testados, sendo duas linhagens isogênicas de sorgo granífero (CMS-XS 114, com tanino, e CMS-XS 165, sem tanino) e dois híbridos de sorgo (BR 700, com tanino, e BR 601, sem tanino). A escolha dessas cultivares foi baseada na presença ou ausência dos taninos condensados nos grãos. Elas foram plantados nas dependências da Embrapa Milho e Sorgo, localizada no Km 65 da rodovia MG 424, no município de Sete Lagoas -MG. O plantio dos genótipos utilizados foi feito em parcelas com dez fileiras de dez metros cada e espaçamento de $0,7 \mathrm{~m}$ entre linhas. A adubação constou de $350 \mathrm{Kg}$ de 8-28-16 no plantio e, após 40 dias, $110 \mathrm{Kg}$ de uréia em cobertura. Os materiais graníferos e o BR 700 foram colhidos nos estádios pastoso e farináceo/duro, respectivamente, e o BR 601, no estádio leitoso. Os materiais foram cortados manualmente, rente ao solo, e imediatamente ensilados em tambores metálicos com capacidade para 200 litros cada, revestidos internamente com sacos de plástico, compactados sob pisoteio e vedados com o auxílio de travas nas tampas. Parte da silagem de cada cultivar foi amostrada, submetida à présecagem em estufa de ventilação forçada a $55^{\circ}$ C, por 72 horas, e, posteriormente, moída em moinho dotado de peneira de $5 \mathrm{~mm}$. Os materiais foram armazenados em frascos de polietileno e, posteriormente, incubados no rúmen de ovinos.

$\mathrm{O}$ experimento com os animais foi conduzido nas dependências do Departamento de Zootecnia da Escola de Veterinária da Universidade Federal de Minas Gerais (UFMG), em Belo Horizonte, sendo utilizados quatro ovinos, fistulados no rúmen, castrados, sem raça definida, com peso aproximado de $35 \mathrm{~kg}$ e idade entre 20 e 28 meses.

Previamente ao início do experimento, os animais foram casqueados e vermifugados e, em seguida, alojados em gaiolas metabólicas. A dieta dos animais foi composta por feno de "Coast-cross" (Cynodon spp) e 300 gramas de concentrado (20\% proteína bruta) por dia.

Os animais foram alimentados em duas refeições diárias (7 e 17 horas), sendo que o feno foi oferecido em quantidade suficiente para que se obtivesse aproximadamente $20 \%$ de sobras no cocho. A água e uma mistura mineral comercial foram administradas ad libitum.

Para incubação, foram utilizados sacos de náilon com porosidade de 50 micras e relação média de $17,5 \mathrm{mg}$ de amostra por $\mathrm{cm}^{2}$ de área superficial dos sacos. Inicialmente, os sacos de náilon foram secados a $65^{\circ} \mathrm{C}$, por 24 horas, e 
seus pesos registrados. Posteriormente, foram preenchidos com $5 \mathrm{~g}$ das silagens estudadas e incubados no rúmen, nos tempos de $6,12,24$, 48, 72 e 96 horas.

Cada animal recebeu 12 sacos de náilon (quatro genótipos em triplicatas) por período de incubação.

Imediatamente após serem retirados do rúmen, os sacos foram imersos em água fria e posteriormente lavados, manualmente, em água corrente em temperatura ambiente, até que essa se mostrasse límpida. Após a lavagem, os sacos foram colocados em bandejas e levados à secagem em estufa de ventilação forçada, por 48 horas, sendo, então, transferidos para um dessecador durante 30 minutos e pesados. Os resíduos de incubação foram moídos em moinho com peneira de $1 \mathrm{~mm}$ e utilizados para determinação de percentagem de fibra insolúvel em detergente neutro (FDN) e percentagem de fibra insolúvel em detergente neutro (FDA), segundo Van Soest et al. (1991), em aparelho ANKOM ${ }^{200}$ Fiber Analyser. Os teores dessas frações nas amostras das forrageiras e dos resíduos de incubação, juntamente com os pesos dos materiais incubados e dos resíduos, foram utilizados para os cálculos do desaparecimento das respectivas frações. As frações solúveis (tempo zero de incubação $\mathrm{t}_{0}$ ) foram determinadas por meio dos mesmos procedimentos, porém sem a incubação ruminal.

Foi utilizado um delineamento experimental de blocos ao acaso, em esquema de parcelas subdivididas, sendo os animais os blocos, as silagens as parcelas e os tempos de incubação as subparcelas.

Para estimar as curvas de degradação, foi utilizado o modelo proposto por Sampaio (1988):

$$
\mathrm{p}=\mathrm{A}-\mathrm{B} \mathrm{e}^{-\mathrm{ct}}
$$

Em que:

$\mathrm{p}=$ porcentagem de degradação após um tempo (t) de incubação no rúmen;

$\mathrm{A}=$ porcentagem máxima de degradação do material contido no saco de náilon, ou degradabilidade potencial

$\mathrm{B}=$ parâmetro sem valor biológico. Se não houvesse tempo de colonização, ele corresponderia ao total a ser degradado pela ação microbiana

$\mathrm{c}=$ taxa constante de degradação da fração que permanece no saco de náilon, expressa em porcentagem por hora

$\mathrm{t}$ = tempo de incubação no rúmen, em horas

A análise dos dados e as equações de regressão para os desaparecimentos dos componentes nutricionais foram feitas utilizando-se o programa Sistema para Análises Estatísticas e Genéticas (SAEG 8.0). O tempo de colonização foi estimado conforme McDonald (1981), de acordo com a seguinte equação:

$$
\mathrm{TC}=\frac{-1}{\mathrm{c}} \times \frac{\ln -\mathrm{S})}{\mathrm{B}}
$$

Em que:

$\mathrm{TC}=$ tempo de colonização, em horas

A, B e c = os mesmos parâmetros definidos na equação anterior 
$\mathrm{S}=$ fração solúvel determinada pela porcentagem de desaparecimento no tempo zero de incubação (fração rapidamente degradada)

As degradabilidades efetivas foram calculadas utilizando-se os valores sugeridos pelo Agricultural Research Council (1984), de 2,0, 5,0 e $8,0 \% \mathrm{~h}^{-1}$ para baixo, médio e alto consumos, respectivamente, segundo o modelo proposto por Ørskov e McDonald (1979):

$$
\mathrm{DE}=\mathrm{S}+[(\mathrm{B} 1 * \mathrm{c}) /(\mathrm{c}+\mathrm{K})]
$$

Em que:

$\mathrm{DE}=$ degradabilidade efetiva, em porcentagem $\mathrm{S}=$ fração rapidamente degradada

B1 = fração degradável calculada subtraindo-se a fração solúvel do potencial de degradação (B1 $=\mathrm{A}-\mathrm{S})$ (fração lentamente degradada)

$\mathrm{c}=$ mesmo parâmetro descrito anteriormente

$\mathrm{K}$ = taxa fracional de passagem, expressa em porcentagem por hora

\section{Resultados e Discussão}

Os valores de desaparecimento médio da FDN das silagens dos genótipos de sorgo são verificados na Tabela 1. Ao avaliar essa tabela, pode-se observar que, até o período de seis horas de incubação, as silagens dos genótipos CMSXS165, CMSXS114 eBR 601 não diferiram entre si $(p>0,05)$ e foram superiores à do $B R$ 700. No entanto, a partir de 12 horas, diferenças foram verificadas. A partir desse período, a silagem da linhagem CMSXS165 foi a que apresentou a maior $(\mathrm{p}<0,05)$ degradabilidade da fração fibrosa e os demais materiais não diferiram entre si $(p>0,05)$, exceto o BR 700, no período de 72 e 96 horas de incubação, com valores inferiores $(p<0,05)$ aos encontrados para o BR 601 e o CMSXS114 ( $>00,05)$.

Campos et al. (2003), avaliando a degradabilidade in situ da silagem de quatro genótipos de sorgo com e sem tanino, encontraram valores de desaparecimento da FDN no período de 96 horas variando de 53,6 a $58,5 \%$. Os valores apresentados pelos autores foram semelhantes aos da silagem da linhagem CMSXS165 e superiores aos das silagens do BR700, BR 601 e CMSXS114. Os valores de desaparecimento da FDN encontrados por Carneiro et al. (2002), em silagens de milho, sorgo e girassol, no período de 96 , horas foram, respectivamente, $81,5 \%, 73,2 \%$ e 40,7\% Quando comparados os valores deste experimento, os valores desse trabalho foram inferiores aos de milho e sorgo e semelhantes ao de girassol.

Quando comparadas as linhagens isogênicas, o maior valor de degradação da FDN foi para a silagem da linhagem CMSXS165, sem tanino, sugerindo que os taninos possam interferir na degradabilidade das frações fibrosas.

Os potenciais de degradação, as taxas de degradação, frações degradáveis, os tempos de colonização e as degradabilidades efetivas da FDN são apresentados na Tabela 2 e podese observar que os potenciais de degradação variaram de 59,19\%, para a silagem da linhagem CMSXS165, a 30,90\%, para a silagem do BR700. Quanto às taxas de degradação, a silagem do genótipo BR700 (6,89\%/h) foi superior às demais, sendo seguido pela 
TABELA 1. Desaparecimento médio (\%) da fibra em detergente neutro(FDN) das silagens de quatro genótipos de sorgo, em função dos tempos de incubação ${ }^{1}$

\begin{tabular}{ccccc}
\hline \multirow{2}{*}{ Horários } & \multicolumn{4}{c}{ Genótipos } \\
\cline { 2 - 5 } & CMSXS 165 & BR 601 & BR 700 & CMSXS 114 \\
\hline 06 & $7,73 \mathrm{Fa}$ & $6,35 \mathrm{Fa}$ & $2,84 \mathrm{~Eb}$ & $5,43 \mathrm{Fa}$ \\
12 & $17,88 \mathrm{Ea}$ & $11,55 \mathrm{~Eb}$ & $12,12 \mathrm{Db}$ & $11,48 \mathrm{~Eb}$ \\
24 & $29,17 \mathrm{Da}$ & $19,92 \mathrm{Db}$ & $22,90 \mathrm{Cb}$ & $20,55 \mathrm{Db}$ \\
48 & $45,71 \mathrm{Ca}$ & $29,95 \mathrm{Cb}$ & $28,76 \mathrm{Bb}$ & $32,09 \mathrm{Cb}$ \\
72 & $52,44 \mathrm{Ba}$ & $35,19 \mathrm{Bb}$ & $29,80 \mathrm{Abc}$ & $37,14 \mathrm{Bb}$ \\
96 & $56,07 \mathrm{Aa}$ & $43,50 \mathrm{Ab}$ & $32,22 \mathrm{Ac}$ & $44,39 \mathrm{Ab}$ \\
\hline
\end{tabular}

${ }^{1}$ Médias seguidas por letras maiúsculas iguais, na mesma coluna, e minúsculas, na mesma linha, não diferem estatisticamente entre si, pelo teste SNK $(p>0,05) . \mathrm{CV}=6,70 \%$

linhagem CMSXS165 (3,10\%), CMSXS114 $(2,13 \%)$ e BR $601(1,63 \%)$. A menor taxa de degradação da silagem do BR601 pode ser atribuída a características físicas e estruturais da sua parede celular, capazes de dificultar o acesso microbiano a essa fração (Van Soest, 1994). Já com relação às frações degradáveis da FDN, a silagem do genótipo CMSXS165 apresentou valor superior, de 57,03\%, sendo seguida pela silagem da linhagem CMSXS114, de $47,91 \%$, pela silagem do BR 601 , de $42,90 \%$, e pelo BR 700 de 27,09\%. Apesar de ser um componente estrutural e, logo, insolúvel (Van Soest, 1994), foi observada uma fração solúvel para a fibra em detergente neutro (FDN). Essa pequena solubilidade da FDN encontrada neste experimento poderia ser explicada pela falta de homogeneidade no preparo das amostras para incubação, no qual a moagem em peneira com malha de abertura de $5 \mathrm{~mm}$ promoveu uma excessiva quebra das diferentes partes da planta de sorgo, aumentando a proporção de partículas que escapariam através dos poros da bolsa de náilon sem serem degradadas (Serafim, 1998; Lara, 1999).

Considerando diferentes genótipos de sorgo (Rabelo, 1997; Serafim et al., 2000; Molina et al., 2002), verifica-se que, na maioria dos casos, a perda da FDN no $\mathrm{t}_{0}$ está entre 4 e $21 \%$, e valores próximos foram verificados no presente experimento. As degradabilidades efetivas da FDN para as silagens de sorgo deste experimento, nas taxas de passagem de 2, 5 e $8 \% / h$ foram de $36,81,23,97$ e $18,07 \%$, para o CMSXS165; 29,17, 20,45 e 17,16\%, para o BR 601; 24,81, 19,51 e 16,35\%, para o BR700, e 26,50, 16,11 e 11,88\%, para o CMSXS114.

Campos et al. (2003), avaliando degradabilidade in situ das silagens de sorgo com e sem tanino, encontraram valores de degradabilidade efetiva(DE) para o BR 701, com tanino, de 39,10, 29,40 e 25,70\%, nas taxas de passagem de 2,5 e $8 \% \mathrm{~h}^{-1}$, respectivamente. Já Lara (1999) encontrou valores de DE variando 
TABELA 2. Potenciais de degradação (A), taxas de degradação (c), frações solúveis (S), frações degradáveis (B1), tempos de colonização (TC) e degradabilidades efetivas (DE), nas taxas de passagem $2,0 \% \mathrm{~h}^{-1}, 5,0 \% \mathrm{~h}^{-1}$ e $8,0 \% \mathrm{~h}^{-1}$, da fibra em detergente neutro das silagens de quatro genótipos de sorgo

\begin{tabular}{ccccc}
\hline \multirow{2}{*}{ Parâmetros } & \multicolumn{4}{c}{ Genótipos } \\
\cline { 2 - 5 } & CMSXS 165 & BR 601 & BR 700 & CMSXS 114 \\
\hline A (\%) & 59,19 & 52,79 & 30,90 & 49,73 \\
c (\%/h) & 3,10 & 1,63 & 6,89 & 2,13 \\
S (\%) & 2,15 & 9,89 & 3,81 & 1,82 \\
B1 (\%) & 57,03 & 42,90 & 27,09 & 47,91 \\
TC (h) & 2,38 & 9,87 & 6,54 & 1,75 \\
DE 2,0\% h ${ }^{-1}(\%)$ & 36,81 & 29,17 & 24,81 & 26,50 \\
DE 5,0\% h-1\%) & 23,97 & 20,45 & 19,51 & 16,11 \\
DE 8,0\% $\mathrm{h}^{-1}(\%)$ & 18,07 & 17,16 & 16,35 & 11,88 \\
$\mathrm{R}^{2}$ & 0,99 & 0,97 & 0,98 & 0,97 \\
\hline
\end{tabular}

de 45,8 a $54,14 \%$, para uma taxa de $2 \% \mathrm{~h}^{-1}, 37,57$ a $46,36 \%$ para uma taxa de $5 \% \mathrm{~h}^{-1}$ e de 34,55 a $43,06 \% \mathrm{~h}^{-1}$ para uma taxa de $8 \% \mathrm{~h}^{-1}$, em silagens de sorgo. Os valores encontrados pelos autores citados foram superiores ao deste experimento, para todos os genótipos avaliados.

Ao comparar as degradabilidades efetivas da FDN das linhagens isogênicas, verificou-se que a presença do tanino pode ter sido a responsável pelos menores valores de DE obtidos para a linhagem CMSXS 114, com tanino $(p<0,05)$. Esse mesmo efeito pode ser verificado quando comparadas as degradabilidades dos híbridos BR 601 (sem tanino) e BR 700 (com tanino) e, ainda, ao comparar a degradabilidade da FDN da linhagem CMSXS 114 (com tanino) e do híbrido BR 601 (sem tanino), sugerindo que os taninos podem exercer efeitos na redução da degradabilidade efetiva da FDN.

Na Tabela 3, são descritos os valores de degradabilidade da fibra em detergente ácido. Pode-se observar que, durante o período de seis horas de incubação, a degradabilidade da fibra em detergente ácido da silagem do genótipo CMSXS165 foi semelhante $(p>0,05)$ à do CMSXS114 e do BR 601 e superior $(p<0,05)$ à do BR 700, que, por sua vez, foi semelhante $(p>0,05)$ à do CMSXS114 e do BR 601. No entanto, a partir de 12 horas, a silagem da linhagem CMSXS165 foi a que apresentou a maior $(p<0,05)$ degradabilidade da FDA e os demais materiais não diferiram entre si $(p>0,05)$, exceto o BR 700 , no período de 48, 72 e 96 horas de incubação, com valores inferiores $(\mathrm{p}<0,05)$ aos encontrados para o BR 601 e o CMSXS114 ( $p>0,05$ ). Com o avançar dos tempos de incubação, houve uma aumento 
TABELA 3. Desaparecimento médio (\%) da fibra em detergente ácido (FDA) das silagens de quatro genótipos de sorgo, em função dos tempos de incubação ${ }^{1}$

\begin{tabular}{ccccc}
\hline \multirow{2}{*}{ Horários } & \multicolumn{4}{c}{ Genótipos } \\
\cline { 2 - 5 } & CMSXS 165 & BR 601 & BR 700 & CMSXS 114 \\
\hline 06 & $5,02 \mathrm{Fa}$ & $2,78 \mathrm{Fab}$ & $1,26 \mathrm{~Eb}$ & $2,91 \mathrm{Fab}$ \\
12 & $15,14 \mathrm{Ea}$ & $8,36 \mathrm{~Eb}$ & $7,19 \mathrm{Db}$ & $8,95 \mathrm{~Eb}$ \\
24 & $26,91 \mathrm{Da}$ & $17,32 \mathrm{Db}$ & $17,51 \mathrm{Cb}$ & $19,26 \mathrm{Db}$ \\
48 & $44,11 \mathrm{Ca}$ & $28,70 \mathrm{Cb}$ & $22,99 \mathrm{Bc}$ & $30,31 \mathrm{Cb}$ \\
72 & $50,84 \mathrm{Ba}$ & $33,16 \mathrm{Bb}$ & $23,94 \mathrm{Abc}$ & $33,98 \mathrm{Bb}$ \\
96 & $54,40 \mathrm{Aa}$ & $40,98 \mathrm{Ab}$ & $26,40 \mathrm{Ac}$ & $40,77 \mathrm{Ab}$ \\
\hline
\end{tabular}

${ }^{1}$ Médias seguidas por letras maiúsculas iguais, na mesma coluna, e minúsculas, na mesma linha, não diferem estatisticamente entre si, pelo teste SNK $(\mathrm{p}>0,05)$.

da degradabilidade da FDA para as silagens de todos os genótipos, sem tendência de estabilização, exceto o BR 700, que estabilizou a degradação da FDA com $72 \mathrm{~h}$ de incubação.

Campos et al. (2003), avaliando a degradabilidade in situ da silagem de quatro genótipos de sorgo come sem tanino, encontraram valores de 32,9, 45,1 e 53,8\%; 33,5, 47,3 e $55,3 \% ; 30,1 ; 47,5$ e $56,8 \%$ e $25,2,45,1$ e $53,2 \%$, para os genótipos CMSXS210, BR 701, BR 007 e CMSXS214, respectivamente, nos tempos de 48, 72 e 96 horas de incubação. Semelhante ao encontrado neste trabalho, os autores não verificaram estabilização da fermentação da fração FDA. Os valores encontrados pelos autores foram semelhantes aos observados para a linhagem CMSXS165 e superiores aos demais materiais deste experimento. Magalhães et al. (2005), avaliando a degradabilidade ruminal de quatro genótipos de sorgo, encontraram valores de 36,9 a $45,72 \%$ e 40,25 a $48,36 \%$, para os períodos de 72 e 96 horas de incubação. Os valores apresentados pelos autores foram semelhantes aos observados para a linhagem CMSXS165 e superiores aos dos demais genótipos utilizados neste trabalho.

Os parâmetros de cinética de degradação da fibra em detergente ácido são demonstrados na Tabela 4, na qual se observa que os valores de potencial de degradação da FDA foram de $57,62 \%$ para a silagem do genótipo CMSXS165, $48,23 \%$ para a silagem do BR 601, 25,34\% para o BR 700 e 42,95\% para o CMSXS114. A maior taxa de degradação foi verificada para a silagem do BR 700, de 5,91\%/h, sendo seguida pela silagem da linhagem CMSXS165 $(3,12 \% / h)$, CMSXS114 (2,68\%/h) e BR 601 $(1,85 \% / h)$. As frações solúveis obtidas para as silagens avaliadas foram pequenas e podem ser atribuídas a erros inerentes à técnica in situ, como passagem de partículas pelos poros do 
TABELA 4. Potenciais de degradação (A), taxas de degradação (c), frações solúveis (S), frações degradáveis (B1), tempos de colonização (TC) e degradabilidades efetivas (DE), nas taxas de passagem $2,0 \% \mathrm{~h}^{-1}, 5,0 \% \mathrm{~h}^{-1}$ e $8,0 \% \mathrm{~h}^{-1}$, da fibra em detergente ácido das silagens de quatro genótipos de sorgo

\begin{tabular}{ccccc}
\hline \multirow{2}{*}{ Parâmetros } & \multicolumn{4}{c}{ Genótipos } \\
\cline { 2 - 5 } & CMSXS 165 & BR 601 & BR 700 & CMSXS 114 \\
\hline A (\%) & 57,62 & 48,23 & 25,37 & 42,95 \\
c (\%/h) & 3,12 & 1,85 & 5,91 & 2,68 \\
S (\%) & 1,31 & 0,88 & 0,46 & 1,30 \\
B1 (\%) & 56,31 & 47,36 & 24,91 & 41,65 \\
TC (h) & 3,61 & 2,97 & 5,76 & 4,28 \\
\hline
\end{tabular}

saco de náilon.

As degradabilidades efetivas da fração FDA, obtidas para as taxas de passagem de 2,5 e $8 \% / h$, foram de 35,$63 ; 22,95$ e $17,12 \%$, para a silagem do CMSXS165; 23,65, 13,68 e 9,78\%, para a silagem do BR 601; 19,07, 13,95 e $11,04 \%$, para a silagem do BR 700 e 25,13 , 15,82 e 11,74\%, para a silagem do CMSXS114..

Magalhães et al. (2005), avaliando a degradabilidade in situ de silagens de sorgo, encontraram valores de DE da FDA nas taxas de passagem de 2,5 e $8 \% \mathrm{~h}^{-1}$ de $34,56,31,16$ e $28,78 \% ; 21,50,20,22$ e $19,23 \% ; 35,50$, 33,29 e $31,76 \%$ e $34,81,34,16$ e $33,61 \%$, para os genótipos Volumax, CMSXS217 9929012, ATF54 9929036 e ATF53 9929036, respectivamente. Os valores encontrados por esses autores foram superiores aos deste experimento. Molina (2000) observou variações de 31,39 a $45,15 \%\left(\right.$ para $\left.2 \% \mathrm{~h}^{-1}\right)$, de 18,23 a $33,81 \%\left(\right.$ para $5 \% \mathrm{~h}^{-1}$ ) e de 13,41 a $29,64 \%$ (para $\left.8 \% \mathrm{~h}^{-1}\right)$. Quando comparados com os dados deste experimento, os valores apresentados por Molina (2000) foram semelhantes aos da linhagem CMSXS165 e superiores aos demais.

As diferenças nos resultados médios de DE da FDA, dos genótipos de sorgo avaliados, podem ser justificadas pelas diferenças no potencial de digestão das diferentes proporções de componentes estruturais. Segundo Campos et al. (2003), o fator de maior efeito sobre a extensão e a taxa de degradação da parede celular dos vegetais é a presença de lignina, sendo observada uma correlação negativa entre degradabilidade da matéria orgânica no rúmen e a lignina. Isso ajuda a explicar os baixos valores de DE da FDN e FDA do BR 700, que, conforme mencionado anteriormente, foi colhido em um estádio de maturação mais avançado.

Além da lignina, os compostos fenólicos como os taninos têm sido apontados como uma barreira primária para a degradação das frações 
fibrosas, estando a redução de sua concentração relacionada positivamente com a digestão. Pires (2003) observou redução da digestibilidade aparente da FDN e FDA de silagens de sorgo com tanino nos grãos. Quando comparadas as DE da FDA das linhagens isogênicas utilizadas neste experimento, a linhagem CMSXS165, sem tanino, foi superior à CMSXS114, em todas as taxas de passagem, sugerindo que os taninos condensados presentes em silagens de sorgo comprometem a degradabilidade da fração fibrosa.

\section{Conclusões}

O tanino influenciou negativamente a degradabilidade ruminal, ao se comparar os materiais de sorgo com presença e ausência desse polifenol.

\section{Literatura Citada}

AGRICULTURAL RESEARCH COUNCIL. The nutrient requirements of ruminant livestock. Slough: Commonwealth Agricultural Bureaux. 1984. 45 p. (Supplement, 1).

BARBOSA, G. S. S. C. Influência das condições experimentais sobre a estimativa de parâmetros do modelo de Orskov para avaliação de digestibilidade em ruminantes. 1996. 74p. Dissertação (Mestrado em Zootecnia) - Escola de Veterinária, Universidade Federal de Minas Gerais, Belo Horizonte.

CAMPOS, W. E.; SATURNINO, H. M.; SOUZA, B. M.; GONÇALVES, L. C.; BORGES, I.; RODRIGUES, J. A. S.; CARVALHO A. U.; FERREIRA, P. M.. Degradabilidade in situ da silagem de quatro genótipos de sorgo com e sem tanino. II - Fibra detergente neutro, fibra detergente ácido, hemicelulose e celulose. Arquivo Brasileiro Medicina Veterinária e Zootecnia, Belo Horizonte, v..55, n. 4, p. 450453, 2003.

CARNEIRO, J. C. C.; OLIVEIRA, E.; SILVA, J. O.; VIANA, A. C. et al. Avaliação da degradabilidade in situ da matéria seca e da fibra em detergente neutro de silagens de milho ("Zea mays"), sorgo ("Sorghum bicolor") e girassol ("Helianthus annuus") In: REUNIÃO ANUAL DA SOCIEDADE BRASILEIRA DE ZOOTECNIA, 39., 2002, Recife. Anais... Recife: SBZ, 2002. CDROM.

HUNTINGTON, J. A.; GIVENS, D. I. The in situ technique for studying the rumen degradation of feeds: reviews of the procedure. Nutrition Abstracts and Reviews Series B - Livestock Feeds and Feeding, Farnham Royal, v. 65, n. 2, p. 63-93, 1995.

LARA, A. C. Degradabilidade in situ dos componentes nutricionais das silagens do sorgo BR 601 colhido em três estádios de maturação. 1999. 67 f. Dissertação (Mestrado em Zootecnia). Escola de Veterinária, Universidade Federal de Minas Grais, Belo Horizonte.

MAGALHÃES, R. T.; GONÇALVES, L. C.; RODRIGUES, J. A. S. et al. Estimativa da degradabilidade ruminal de quatro genótipos de sorgo (Sorghum bicolor (L.) Moench) utilizando a técnica in situ. Acta Science Animal Science. Maringá, v. 27, n. 4, p. 483490, 2005.

McDONALD, J. A revised model for the estimation of protein degradabitility in the rumen. 
Journal Agriculture Science, Cambridge, v. 96, n. 1, p. 251-252, 1981.

MOLINA, L. R.; GONÇALVES, L. C.; RODRIGUES, N. M. et al. Digestibilidade in situ das frações fibrosas de silagens de seis genótipos de sorgo (Sorghum bicolor (L) Moench) em diferentes estágios de maturação. Arquivo Brasileiro Medicina Veterinária Zootecnia, Belo Horizone, v. 54, p. 169-179, 2002.

NOCEK, J. E. In situ and other methods to estimate ruminal protein and energy digestibility: a review. Journal Dairy Science, Champaign, v. 71, n. 8, p. 2051-2069, 1988.

ØRSKOV, E. R.; McDONALD, J. The estimation of protein degradability in the rumen from incubation measurements of feed in weighted according to rate of passage. Journal Agriculture Science, Cambridge, v. 92, n. 2, p. 499-503, 1979.

RABELO, E. Degradabilidade in situ de silagens de híbridos de sorgo (Sorghum bicolor (L.) Moench) de porte médio com diferentes teores de tanino e suculência no colmo. 1997. 49 f. Dissertação (Mestrado em Zootecnia) - Escola de Veterinária, Universidade Federal de Minas Gerais, Belo Horizonte.

SAMPAIO, I. B. M. Experimental designs and modelling techniques in the study of roughage degradation in rumen and growth of ruminants. 1988. $214 \mathrm{f}$. Thesis (Doctor of Philosophy) - Univesity of Reading, Reading.

SERAFIM, M. V. Degradabilidade in situ dos componentes nutricionais das silagens de três cultivares de sorgo (BR303, BR601 e BR700). 1998. 44 f. Dissertação (Mestrado em Zootecnia) - Escola de Veterinária, Universidade Federal de Minas Gerais, Belo Horizonte.

SERAFIM, M. V.; BORGES, I.; GONÇALVES, L. C. et al. Desaparecimento in situ da matéria seca, proteína bruta e fração fibrosa das silagens de híbridos de sorgo (Sorghum bicolor (L.) Moench). Arquivo Brasileiro Medicina Veterinária Zootecnia, Belo Horiznte,v. 52, p. 634-640, 2000.

THIAGO, L. R. L. S. Utilização da técnica de degradabilidade in situ para avaliação de forragens e alimentos concentrados. In: SIMPÓSIO INTERNCIONAL DE PRODUÇÃO DE RUMINANTES, 1994, Maringá. Anais... Maringá: EDUEM, 1994. p. 89-93.

VAN SOEST, P. J. Nutritional ecology of the ruminant. 2. ed. Ithaca: Cornell University Press. 1994. 476 p.

VAN SOEST, P. J.; ROBERTSON, J. B.; LEWIS, B. A. Methods for dietary fiber, neutral detergent, and nonstarch polysaccharides in relation to animal nutrition. Journal Dairy Science, Champaign, v. 74, n. 10, p. 3583-3597, 1991. 
